\title{
ANTROPOLOGIA E IMAGEM SOBREVIVENTE NA OBRA DE ABY WARBURG
}

\author{
Ana Paula Oliveira ${ }^{1}$ \\ Tatiana Romagnolli Peres ${ }^{2}$
}

\section{Introdução}

Diante da quantidade infinita de imagens a que o homem passou a ter acesso na atualidade, surge a necessidade de se pensar sobre as origens e efeitos produzidos por tais objetos. Esta necessidade é atribuída ao fato de que estas imagens, dos mais diferentes meios e formatos, contribuem também para entendimento do homem e de seu entorno social e cultural.

Por se tratar de um dos princípios elementares da antropologia, esta orientação será então tomada como núcleo fundamental do presente estudo. De modo mais específico, esta pesquisa irá se propor a repensar as contribuições e as posturas adotadas pelo historiador da arte Aby Warburg, a partir de um olhar antropológico. Toda a sua extensa pesquisa sobre modos de reaparecimento de determinadas imagens em movimento ao longo da história e da arte tiveram sua origem ligada à pesquisa antropológica. Desta forma, será analisada a relevância de estudos antropológicos para o conceito warburguiano de pós-vida das imagens.

Neste sentido, a arte e a imagem seriam vistas como parte constituinte de uma memória viva e pulsante e, por isso, abordadas pela perspectiva warburguiana. Para este historiador e pesquisador, a imagem poderia ser percebida como uma reminiscência por meio da qual ele institui uma ligação permanente entre culturas aparentemente distintas. Desta maneira, as imagens estariam aptas a refletir a cultura ou serem refletidas por ela. Na perspectiva de Warburg, partes destes elementos culturais sobreviveriam através da história por meio das imagens em movimento.

Como fonte primária para este estudo, teremos anotações diárias, diários de campo, cartas escritas a amigos e familiares teses e teorias deixadas por Warburg ao longo de sua carreira. Com o auxílio de imagens fotográficas e textos, é possível compreender a proposta deste pesquisador sobre a pós-vida das imagens que suscita uma ligação direta com estudos da antropologia visual.

\footnotetext{
${ }^{1}$ Universidade Estadual de Londrina, Brasil.

${ }^{2}$ Universidade Estadual de Londrina, Brasil.
} 
Todos estes apontamentos e considerações serão respaldados por uma pesquisa bibliográfica. No entanto, faz-se necessário compreender que Warburg publicou poucos trabalhos ao longo de sua carreira apesar de ter se debruçado sobre uma pesquisa bastante ampla e profunda. De todas as suas contribuições, pouco foi oficialmente publicado. Muitas das ideias suscitadas por este historiador provêm de textos de autores próximos a ele, discípulos que ousaram assumir e dar continuidade a suas pesquisas. Dentre as muitas elaborações relevantes, destacam-se trechos de seus diários e imagens fotográficas por ele obtidas durante sua viagem aos Estados Unidos e que foram postumamente publicados. Certamente, estes textos irão contribuir para a comprovação de sua estreita ligação com referências antropológicas e necessidade de utilização destas teorias.

Este trabalho irá se apropriar e amparar-se em teóricos e teorias relevantes como: Geertz (A interpretação das Culturas) ao propor a elaboração de uma ciência interpretativa da cultura e do fazer etnográfico; Didi-Huberman (A imagem sobrevivente) que comenta profundamente sobre os fundamentos da constituição da teoria warburguiana; Baitello Junior (A serpente, a maçã e o holograma) ao discorrer sobre as conexões promovidas pelas teorias de Warburg e, também, sobre os rituais indígenas pagãos; Michaud (Aby Warburg e a imagem-movimento) que referencia, entre muitas informações, trechos de textos escritos pelo próprio Warburg justificando sua pesquisa; Novaes ( $\mathrm{O}$ uso da imagem em antropologia) ao proporcionar conexões pertinentes ao uso da imagem em pesquisa antropológica e Samain (As "Mnemosynes" de Aby Warburg) ao ponderar o uso da imagem e da estética nos estudos antropológicos.

Com base nesta pesquisa bibliográfica, este artigo terá como objetivo principal identificar e apresentar as possíveis conexões percebidas entre a elaboração das teorias warburguianas, o uso de metodologias antropológicas e a necessidade das relações entre imagem, cultura e antropologia. Entendendo, por consequência, como a imagem e a arte também podem contribuir para a efetivação do trabalho antropológico.

Neste esforço por determinar as relações entre os já citados objetos de pesquisa, residirá uma preocupação bastante importante com distinções e conceitos sobre antropologia, antropologia visual, imagens enquanto portadoras de significados subjetivos, função das imagens em antropologia, breves relatos sobre o pesquisador Aby Warburg e suas teorias e finalmente as pistas que levam à comprovação de suas ideias por meio de uma profunda pesquisa antropológica. 
A antropologia, que surgiu com o objetivo de pensar o homem a partir da análise de suas diferenças, passa posteriormente a perceber o poder informacional das imagens, permitindo que passemos a utilizá-las como fonte de pesquisa, de costumes ou da cultura de determinados grupos ou épocas distintas. Por isso, a antropologia visual sugere não somente olhar as imagens, mas perceber o caráter cultural, implícito ou subjetivo, e assim lê-las como textos.

De acordo com Flusser (2007), imagens são superfícies e assim como as linhas, possuem códigos e, consequentemente, conteúdo comunicacional. Os códigos das superfícies são abertos, o que possibilita uma infinidade de leituras que dependem até mesmo, do repertório do leitor. Estes códigos são efêmeros, variando de acordo com a época ou período no qual estão inseridos.

Em antropologia, uma das funções das imagens é a de portar informações específicas referentes a certos grupos. Ela pode ser utilizada e coletada no trabalho de campo do antropólogo como forma de amparar, conduzir e contribuir para a pesquisa antropológica. Imagens produzidas por ou sobre certos grupos permitem uma infinidade de possibilidades na pesquisa antropológica.

Aby Warburg (1866-1929) foi um pesquisador e historiador da arte alemão que buscou demonstrar por meio de suas pesquisas imagéticas e artísticas, a existência em certas imagens de camadas extremamente profundas e arraigadas a elementos precedentes. Para isto, precisou mergulhar profundamente nas questões antropológicas.

A percepção e conexão entre alguns elementos de imagens pagãs com outros ressurgidos durante o Renascimento foi citada por Warburg ao propor a pós-vida ou sobrevivência desta Antiguidade. Em razão da busca por esta constatação, precisou perceber e destacar a representação de elementos em movimento, recorrentes em diferentes culturas. $\mathrm{O}$ plano central dos trabalhos de sua tese remetem a reflexões sobre a Nachleben (pós-vida das imagens).

Importante se faz realçar que estes estudos sobre a sobrevivência de elementos imagéticos pagãos da Antiguidade Clássica no Renascimento, propostos por Warburg, só foram possíveis graças a uma pesquisa antropológica profunda e uma imersão em grupos como os dos índios Hopi e os Pueblos, que ainda mantinham de maneira intacta certos rituais. Ao conviver entre eles, compreender parte de sua cultura e desenvolver um diário de campo, o historiador da arte Aby Warburg desenvolveu claramente um trabalho etnográfico e antropológico. 


\section{Imagem como sistema comunicacional}

Muitas são as funções ou definições atribuídas à imagem: meio de expressão, comunicação, registro histórico, cópia do real, simulacros, entre infinitas outras. Para Flusser (2007), imagens são superfícies que representam algo e como tal, possuem um conteúdo passível de leitura. Estas superfícies (fotografias, pinturas, vitrais ou inscrições rupestres) possuem uma quantidade ilimitada de informações que contam e carregam o mundo em que vivemos. São, portanto, elementos importantes do processo de comunicação humana.

Faz-se necessário, para compreensão do mundo circundante, ler e entender tais superfícies como também o fazemos com as linhas, ou seja, com a escrita. A diferença fundamental situa-se na forma de leitura, ambas podem ser lidas - linhas ou superfícies - contudo a superfície possui códigos abertos e subjetivos. Sendo assim, o suposto leitor pode obter por meio da leitura destas superfícies várias interpretações que variam de acordo com a vivência ou repertório de cada um.

Contudo, os códigos são elementos comunicacionais transitórios e efêmeros, pois se modificam constantemente. Sobre a transitoriedade dos códigos e a necessidade de decifração dos mesmos, Flusser (2007: 129) contribui ao afirmar que "como os códigos em geral são efêmeros (como, por exemplo, a língua falada, os gestos, os cantos), somos levados a decifrar sobretudo o significado das imagens [...]”. Para o autor, este código em superfície sempre existiu e como consequência sempre retratou o mundo, assim como as linhas o retrataram. Importante se faz mencionar tanto a relevância destes códigos para a comunicação, quanto seu valor simbólico: "Um código é um sistema de símbolos. Seu objetivo é possibilitar a comunicação entre os homens. Como os símbolos são fenômenos que substituem ('significam') outros fenômenos, a comunicação é, portanto, uma substituição [...]” (Flusser, 2007: 130).

Ao retratarem o mundo, as superfícies imagéticas, do mesmo modo, servem de respaldo para a percepção e compreensão deste mesmo mundo, daí sua relação direta com a antropologia visual. De acordo com Ribeiro (2005: 621), "a primeira função das imagens em antropologia foi (e é) documentar, isto é, criar algo portador de informação que traz em si a inscrição e o registro de um acontecimento observável ou verificável”.

Partindo-se da constatação de que imagens estão impregnadas de conteúdos simbólicos e consequentemente de referências culturais, pode-se perceber seu verdadeiro potencial. Imagens podem contribuir para a ampliação do conhecimento. A 
partir de tais constatações, torna-se clara a importância do uso de imagens pela pesquisa antropológica. Por isso convém ressaltar que tal estudo pode e deve se utilizar de imagens para amparar ou direcionar sua investigação, pois

\begin{abstract}
Imagens, tais como textos, são artefatos culturais. É nesse sentido que a produção e análise de registros fotográficos, fílmicos ou videográficos pode permitir a reconstituição da história cultural de grupos sociais [...]. Assim, o uso da imagem acrescenta novas dimensões à interpretação da história cultural, permitindo aprofundar a compreensão do universo simbólico, que se exprime em sistemas de atitudes por meio dos quais grupos sociais se definem, constroem identidade e apreendem mentalidades. (Novaes, 1998: 116)
\end{abstract}

É possível perceber o quanto as imagens fazem parte de nosso cotidiano simplesmente olhando ao redor. Imagens podem ser vistas nas mais variadas formas e meios de reprodução. Assim sendo elas possuem conteúdos informacionais que podem contribuir para melhor entendimento de determinados grupos, épocas ou períodos distintos. Mas não é somente a contemporaneidade que é refletida em imagens. Em qualquer período histórico, pode-se perceber que a imagem também se apresenta carregada de elementos que refletem a sociedade circundante. Não obstante, elas estabelecem uma conexão e um diálogo com cada momento específico.

Agimos e interagimos com as imagens sem percebermos o quanto elas impregnam o mundo contemporâneo transmitindo e moldando valores fundamentais da nossa cultura. Estas imagens não falam por si sós, mas expressam e dialogam constantemente com modos de vida típicos da sociedade que as produz. (Novaes, 1998: 116)

\title{
O potencial da imagem em antropologia
}

O surgimento da antropologia visual está relacionado ao fato de os pesquisadores perceberam todo o universo de possibilidades informacionais e comunicacionais, explícito ou não, nas imagens. É importante também realçar que estes conteúdos são passíveis de investigação. Faz-se necessário considerar o potencial destas imagens no que concerne ao uso em antropologia. Autores como Ribeiro (2005: 637) atestam o poder de investigação contido nas imagens. Sendo assim, ele afirma que "a antropologia visual apresenta-se como um campo de investigação e de desenvolvimento de práticas".

Para reafirmar a importância das imagens, enquanto portadora e transmissora de conteúdos, algumas referências fazem-se indispensáveis. Entender a relação entre imagem, cultura e antropologia é imprescindível já que todas se relacionam 
frequentemente. Contudo, nota-se que esta relação não é recente. Autores comentam sobre a necessidade do uso de imagens para o estabelecimento de vínculos entre tradição e memória. Sobre a relação entre imagem e cultura e a importância do uso de ambas para o entendimento da história cultural, Novaes (1998: 116) afirma que:

Arquivos de imagens e imagens contemporâneas coletadas em pesquisa de campo podem e devem ser utilizados como fontes que conectam os dados à tradição oral e à memória dos grupos estudados. Assim, o uso da imagem acrescenta novas dimensões à interpretação da história cultural, permitindo aprofundar a compreensão do universo simbólico [...]

Como se há de verificar, o universo contido na análise imagética abrange uma grande diversidade de elementos, permitindo que se abra uma infinidade de possibilidades a serem utilizadas na pesquisa antropológica. Ao se considerar a antropologia visual como uma compreensão de três grandes campos: o das manifestações visuais da cultura (expressão facial, dança, vestuário, objetos, ...); o dos aspectos picturais (pinturas, filmes, fotografias, televisão, ...) e dos meios visuais que tendem a comunicar o saber antropológico (Ribeiro, 2005: 633). O que se permite refletir sobre a inclusão de uma ampla parcela de elementos que se contrapõe a perspectiva linear para comunicação e compreensão dos signos. Todas estas abrangências podem ser constatadas e concretizadas durante o trabalho de campo dos antropólogos.

No entanto, não há como falar sobre antropologia, mesmo visual, sem citar referências que denotem sua prática, seu trabalho de campo e a relação com a etnografia. Por isso, a necessidade de lembrar Clifford Geertz, antropólogo que se debruçou sobre estudos culturais a partir de uma ciência interpretativa e de uma descrição densa. Ele assevera que tais estudos somente são possíveis se o antropólogo realmente viver como um nativo, mergulhando profundamente na cultura do outro, afirmando que o que os antropólogos fazem, na verdade, é etnografia. De acordo com Geertz (1989: 7):

O que o etnógrafo enfrenta, de fato- a não ser quando (como deve fazer, naturalmente) está seguindo as rotinas mais automatizadas de coletar dados — é uma multiplicidade de estruturas conceptuais complexas, muitas delas sobrepostas ou amarradas umas às outras, que são simultaneamente estranhas, irregulares e inexplícitas, e que ele tem que, de alguma forma, primeiro apreender e depois apresentar. 
No entanto, este autor não se deteve em apenas explanar o que para ele seria o propósito de um etnógrafo, mas também enfatizou o que define como trabalho de campo. Dessa maneira, Geertz (1989: 7) indica que, para ele, trabalho de campo seria: "entrevistar informantes, observar rituais, deduzir os termos de parentesco, traçar as linhas de propriedade, fazer o censo doméstico... escrever seu diário. Fazer a etnografia é como tentar ler (no sentido de "construir uma leitura de")".

Cumpre ressaltar que não é somente no campo artístico que as imagens aparecem carregadas de conteúdos informacionais contribuindo para viabilizar várias necessidades inerentes ao homem. Há que se pensar, em função de seu caráter simbólico e informacional, na relevância e necessidade desta imagem de modo generalizado, colaborando de maneira clara para expressão, via de acesso e de informação de seu criador e de seu entorno.

É necessário observar, do mesmo modo, que elas são importantes não somente para o processo de comunicação, mas para entendermos, entre outras elementos, como se constituem certos grupos sociais. Há que se notar que em determinados momentos, esta compreensão ou aproximação somente pode ser possível por meio de um último ou único recurso: imagens produzidas deles ou por eles. Imagens são, também, necessárias quando passam a informar o que, muitas vezes, as palavras não informam. Conteúdos estes que poderão ser analisados pela antropologia. Como constata Novaes (1998: 116):

[...] um dos objetivos mais caros da Antropologia sempre foi o de contribuir para uma melhor comunicação intercultural, o uso de imagens, muito mais do que palavras, contribui para essa meta, ao permitir captar e transmitir o que não é imediatamente transmissível no plano lingüístico. Certos fenômenos, embora implícitos na lógica da cultura, só podem explicitar no plano das formas sensíveis o seu significado mais profundo.

Contudo, há que se notar que, por meio da análise imagética de determinados grupos, é possível contato e conhecimento de vários elementos culturais. Por meio deste levantamento de tendências, estilos, modos, roupas, organização social ou relações, por exemplo, consegue-se entendê-los de modo a proporcionar maiores contribuições, diminuindo as distâncias entre diferentes culturas. Uma das probabilidades é que se a imagem, ou a arte, carrega consigo tantos elementos significativos é por intermédio de seus estudos que também pode se chegar ao âmago das informações culturais.

Por isso, de acordo com Samain (2011), deve-se considerar a relevância e a possibilidade de constituição de um diálogo entre áreas afins, como a arte, a 
antropologia e as imagens, para que haja um entendimento da cultura. $\mathrm{O}$ autor ainda continua afirmando que "é urgente recolocar a arte no epicentro da existência humana, isto é, no centro da cultura, de todas as culturas. Como antropólogo, não posso mais pensar as sociedades humanas e os homens que a fazem sem priorizar a questão da arte e de suas estéticas" (Samain, 2011: 31). E foi nesta busca por conhecimento da cultura por intermédio da imagem que Aby Warburg amparou as pesquisas de toda sua vida.

Philippe-Alain Michaud, em sua obra "Aby Warburg e a imagem-movimento", estabelece pontos nos quais é possível perceber diversos elementos que servem de subsídios para o estabelecimento de uma relação de proximidade entre as práticas de Warburg e a antropologia. Ele cita a necessidade de perceber a imagem como um elemento repleto de interferências que se alteram de acordo com o período ou o lugar a qual esta pertença, e mesmo assim, consegue manter certas ligações, objetivas ou subjetivas, com outras imagens ou outras interferências. Em sua concepção "a imagem não é um campo de um saber fechado. É um campo turbilhonante e centrífugo. Talvez nem seja um "campo do saber" como os outros. É um movimento que requer todas as dimensões antropológicas do ser e do tempo". (Michaud, 2013: 21).

Em função desta proposta, faz-se necessário repensar o modo como a imagem e a arte podem modificar, diferenciar e complementar o trabalho de pesquisa antropológica. E, igualmente, pensar sobre as relevantes teorias, propostas e contribuições do historiador da arte e antropólogo Aby Warburg.

\section{O legado de Warburg}

Aby Warburg (1866-1929) foi um importante historiador da arte alemão, criador de uma proeminente biblioteca de Ciências da Cultura, em Hamburgo na Alemanha. Nesta biblioteca, resultado de um acordo de divisão de herança entre ele e seu irmão, encontrava-se o que Warburg chamou de Atlas Mnemosyne (Figura 1). Uma disposição de reproduções, em preto e branco, de obras de arte, imagens publicitárias e recortes de jornal, por meio da qual buscou recontar a história da cultura utilizando apenas imagens. 


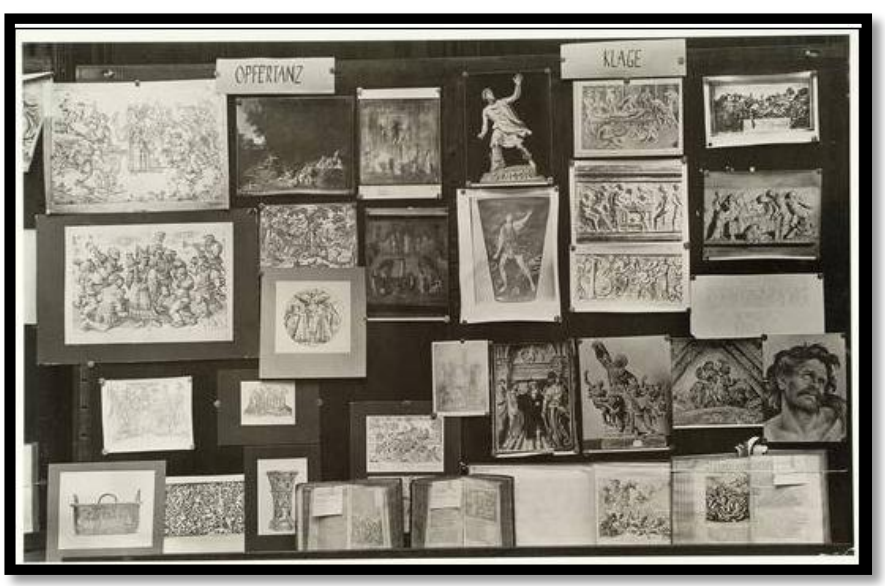

Figura 1 - Prancha do Atlas Mnemosyne ${ }^{3}$.

Para Samain (2011), Warburg propunha novos modos de pensar a imagem, pois a partir de sua pesquisa desenvolveu um trabalho de aproximação entre a arte e a antropologia. É possível notar que esta utilização da antropologia não tenha surgido gratuitamente na vida de Warburg. É sabido que ele foi influenciado, no decorrer de sua carreira, por antropólogos como Franz Boas que, segundo Michaud (2013: 180), foi um dos fundadores da etnologia moderna. $\mathrm{O}$ contato entre ambos ocorreu aproximadamente na segunda metade da década de 80, na América do Norte. Este encontro viria a contribuir para seu posicionamento e olhar cultural.

Nesse sentido, é nítido perceber que "a história da arte tradicional transfigurava-se em uma antropologia do visual" (Samain, 2011: 36). Esta opinião pode ser constatada na fala de outros autores quando comentam sobre o modo inovador que Warburg tinha de recontar a história. Deste modo, é possível notar que a sugestão da tese warburguiana seria de romper com a linearidade proposta pela história da arte e com as extremas rupturas sugeridas até então pelos movimentos e períodos.

\begin{abstract}
Nos anos da sua formação, Warburg absorveu a ideia, defendida com nuances diferentes pelos seus mestres Lamprecht, Usener e Schmarsow, que a história da humanidade se desenvolvia segundo uma evolução linear que partia de um irracionalismo religioso-mágico da época 'primitiva' e procedia progressivamente, em direção ao racionalismo matemático da ciência moderna. Foi precocemente, no entanto, que Warburg se apercebeu que os documentos que a história oferece nem sempre se adaptam a este esquema. (Scarso, 2006)
\end{abstract}

Warburg, por intermédio de suas pesquisas com o Atlas Mnemosyne, buscou demonstrar a existência de uma pós-vida, ou "sobrevivência", das imagens, (Nachlebender antike), que, de acordo com Baitello Junior (2010: 60), refere-se ao

\footnotetext{
${ }^{3}$ Arquivo do Instituto Warburg. Fonte: http://warburg.sas.ac.uk/archive/. Acesso em: 22 de jan. de 2013.
} 
momento em que "elementos se transportam de uma cultura e de uma época para outra". Estes elementos são reutilizados ao longo dos tempos pelas criações imagéticas posteriores e consistem em movimentos ágeis e intensos que exprimem forte paixão. Eles seriam a base para o que Warburg chamou de "Pathosformeln" - "fórmulas patéticas", elementos que teriam a capacidade de mover os afetos e de suscitar emoções através do tempo e da história.

Após-vida das imagens trata de perceber e entender como certas formas pagãs antigas reapareceriam ao longo do século XV e XVI, principalmente em obras como O Nascimento de Vênus (1485), do artista Sandro Botticelli (1446-1510). Esta obra possuiria, segundo Warburg, uma ligação de proximidade com um texto de Ângelo Poliziano - La Giostra, que por sua vez havia sido inspirado num canto homérico. Esta inter-relação entre os textos antigos e a imagem criada por Botticelli com grande intervalo de tempo é o que Warburg denominaria "pós-vida" das imagens. Michaud (2103: 25) destaca esta relação atemporal, ao propor que "o pensamento warburguiano abala a história da arte porque o movimento que abre nela constitui-se de coisas que são, ao mesmo tempo, arqueológicas (fósseis, sobrevivências) e atuais (gestos, experiências)".

Provavelmente, a teoria sobre a Pathosformeln, uma espécie de reminiscência, poderia vir a explicar a relação de sua pesquisa com a antropologia, que também tem como um de seus preceitos a volta ao passado. Estas ideias chegariam a contribuir futuramente para alterações no modo de se pensar a história da arte a partir de uma ciência da cultura - Kulturwissenschaft. Didi-Huberman (2013: 40) assegura que as “fórmulas patéticas" poderiam ser:

Esses gestos intensificados na representação pelo recurso a fórmulas visuais da Antiguidade Clássica [...].

Em suma, a imagem não devia ser dissociada do agir global dos membros de uma sociedade. Nem do saber próprio de uma época. Tampouco, é claro, do crer: aí reside outro elemento essencial da invenção warburguiana, que foi abrir a história da arte para o "continente negro" da eficácia mágica [...]

A ligação de Warburg com a pesquisa do passado remanescente poderia ser vislumbrada e concretizada com a publicação de sua de tese de doutorado, em 1893, intitulada "O nascimento de Vênus e a Primavera de Sandro Botticelli: uma investigação sobre as representações da Antiguidade no início do Renascimento 
italiano". Um dos poucos trabalhos publicados por Warburg, no qual estaria condensada toda a sua teoria sobre pós-vida das imagens.

A busca por comprovar sua tese o levaria, nos anos de 1895-1896, às práticas da pesquisa antropológica. Deve-se levar em consideração o fato de que ele também tinha por objetivo demonstrar que a história da arte não acontecia de modo linear, muito menos isento de influências de períodos antecessores, principalmente quando se referia às influências sofridas pela arte do Renascimento.

De forma geral, para Warburg, o problema residia na explicação da persistência de traços considerados característicos de épocas mais antigas, e portanto, teoricamente ultrapassadas (como por exemplo a ninfa em êxtase, a superstição astrológica ou a prática da adivinhação), em fases 'iluminadas' como o Renascimento e a época contemporânea. É por esta razão que ele começa a elaborar uma perspectiva não evolutiva, que não pressupõe um desenvolvimento linear entre uma fase irracional e mágica e outra racional e científica, quando muito uma humanidade continuamente suspensa entre estas duas 'posturas' fundamentais. (Scarso, 2006)

Todas estas ideias sobre a sobrevivência das imagens apontam que as pesquisas de Warburg caminharam por lugares conhecidos à etnografia ou à antropologia. Tal fato é claramente identificado no momento em que ele, enquanto pesquisador dedicado e atento às necessidades mais fundamentais de seu trabalho, transforma, de acordo com Michaud (2013: 19) sua "pesquisa histórica em deslocamento geográfico e etnológico" através de sua viagem pelo Novo México.

Várias conexões e especificações com outros campos e teorias foram necessárias para constatar a sobrevivência de determinadas formas. Imagens, de modo geral, tiveram um papel crucial em tais constatações. Segundo Didi-Huberman (2013: 35), as imagens para Warburg "viriam a ser consideradas como aquilo que sobrevive de uma dinâmica e uma sedimentação antropológicas tornadas parciais, virtuais, por terem sido, [...], destruídas pelo tempo". Daí a busca por constatar que determinados elementos são transportados pelo tempo e, desta maneira, possam ter sido claramente ou indiretamente influenciados por períodos antecessores.

O modo pelo qual Warburg buscou demonstrar a existência da Nachleben (sobrevivência) o aproxima de um etnógrafo ou antropólogo, já que para ele, as imagens estariam conectadas com os acontecimentos e a cultura que antecedem tais criações. Estas seriam, por consequência, criações que carregam consigo parte da história.

Em suas pesquisas, Warburg buscava encontrar o cultural, o elemento humano, as memórias nas imagens. Esta proposta nos leva a um universo amplo, que não diz 
respeito somente à visão de um historiador da arte, mas a existência de uma percepção antropológica para com a cultura e as imagens.

Significa que, para ele, as imagens não são meros "objetos", nem apenas cortes no tempo e golpes no espaço. São "atos", memórias, questionamentos e, até, como logo veremos, visões e prefigurações. Se as imagens são nossos próprios olhos, elas são, também, os reflexos e os rastros de uma longa história de olhares que nos precederam, os fluxos e refluxos do presente, as pistas e as antevisões da longa aventura humana (Samain, 2011: 40)

Fica claro ao longo das pesquisas de Warburg que seu objetivo era uma tentativa de determinar uma antropologia das imagens, que o levaria ao âmago das criações imagéticas e da cultura, o que, consequentemente, comprovaria sua teoria. Sendo assim, Warburg busca mencionar uma "sobrevivência" por meio da alusão à antiguidade, ao modo certos elementos pagãos reaparecem em criações renascentistas dos séculos XV e XVI. O que é corroborado pelas afirmações de Teixeira (2010: 138):

Seu interesse voltava-se precisamente para a análise das relações complexas entre artista e seu meio, com destaque para papel do comitente na produção artística e a relação dos artistas com modelos literários circulantes, especialmente no que diz respeito ao exame dos mecanismos de transmissão e sobrevivência da memória cultural da Antiguidade.

São fortes os indícios sobre a relevância dos trabalhos e da pesquisa de Warburg sobre a arte e a história, e na relação de ambas com a antropologia como método de pesquisa. Para Didi-Huberman, este suposto deslocamento do objeto artístico tradicional a um "rizoma - de relações" (2013: 38) foi a razão fundamental de seu compromisso com as questões antropológicas. Warburg consegue permitir que imagens e arte sejam amparadas pelo campo antropológico. Continuando a contribuir para o esclarecimento destas questões, Didi-Huberman (2013: 40) afirma que "para Warburg, de fato, a imagem constituía um 'fenômeno antropológico total', uma cristalização e uma condensação particularmente significativas do que era uma 'cultura' [Kultur] num momento de sua história".

\section{A Viagem a América e a pesquisa antropológica}

Entre as várias investidas de Warburg em busca de comprovar suas ideias a respeito da Nachleben der Antique está uma viagem que fizera aos EUA entre os anos de 1895 a 1896. A história começa quando, em 1895, em função de ter que comparecer 
ao casamento de seu irmão mais novo Paul, Warburg viaja para os Estados Unidos. Mais de vinte e cinco anos depois ao redigir uma conferência sobre esta viagem, ele justificaria sua ida às tribos indígenas e o prolongamento de sua viagem à América relatando que:

\begin{abstract}
Olhando de fora, na superfície de minha consciência, eu veria a seguinte causa: é que eu sentia tamanha repugnância pelo vazio da civilização do Leste dos Estados Unidos, que tratei de fugir para as coisas reais e para o saber e aventura, indo a Washington visitar a Smithsosian Institution. Ela é o cérebro e a consciência científica da América ocidental. Ali encontrei, na pessoa de Cyrus Adler e nos senhores Hodge, Frank Hamilton Cushing e, sobretudo, James Mooney (sem esquecer Franz Boas, em Nova York), pioneiros da pesquisa indigenista que me abriram os olhos para a significação universal da América pré-histórica e selvagem. Assim, decidi visitar o Oeste norte-americano, tanto como criação moderna quanto em suas camadas profundas hispano-indígenas.

Minha vontade romântica somou-se à vontade de encontrar uma ocupação mais física do que me fora dado exercer até então. (Warburg apud Michaud, 2013: 179180)
\end{abstract}

Em suas descrições e relatos a respeito de sua passagem pela América do Norte, Warburg faz várias considerações sobre sua ida a capital Washington onde pôde visitar o renomado Smithsonian Institution, um gigantesco complexo de pesquisa e museus. Lá ele se deparou com uma imensa quantidade de material sobre os ameríndios e com várias pesquisas etnográficas que o remeteram não somente às reminiscências de sua formação antropológica em Bonn, mas também a uma busca por encontrar indícios da existência de rituais primitivos. Estes rituais o conectariam diretamente a uma reconstituição do passado. Warburg assumiria em seus escritos a importância e a necessidade de seu contato com grupos mais isolados em que ainda perpetuavam determinadas tradições, ao revelar que:

O que há de essencialmente novo em minha teoria é a ideia de que a memória está presente não uma única vez, e sim várias, e se compõe de diversos tipos de 'sinais'. (...) A defesa patológica só se volta contra os traços mnêmicos ainda não traduzidos e pertencentes a uma fase anterior. (...) Vemo-nos, assim, na presença de um anacronismo [Anachronismus]: numa dada província, ainda existem fueros, sobreviveram vestígios do passado [...]. (Didi-Huberman, 2013: 274)

Seria do contato direto com este passado imaculado e ainda vivo que ele conseguiria constatar a preservação das ligações entre passado e presente, as ligações simbólicas que tanto defendia. Sobre a relevância do contato deste pesquisador com seus pares do Smithsonian Institute, Alves (2005: 15) asseverou: 
O jovem visitante dos Estados Unidos, ao encontrar Boas, Holmes, Powell, Cushing e Mooney, no Smithsonian Institute, teria vislumbrado por um momento a possibilidade de se tornar antropólogo e segue os conselhos desses fundadores da disciplina nos Estados Unidos ao partir para o Arizona em sua busca pelos índios Hopi.

Por intermédio desta incursão desbravadora pelos Estados Unidos (Figura 2), Warburg entra em contato com diversas tribos indígenas, entre as quais estão os Pueblos e os Hopi (Figura 3). As conexões proporcionadas por esta visita podem ser lidas em seus diários. Nelas ele explica também sobre seu trabalho em busca das bases para a comprovação de sua tese sobre a pós-vida das imagens, como pode ser notado em um trecho de uma destas cartas em que relata a tão almejada busca pela comprovação da existência de rituais primitivos "poupados de qualquer teatralidade" (Michaud, 2013: 217).

[...] depois de minha viagem à América, a relação orgânica entre arte e religião nos povos "primitivos" me apareceria com tamanha clareza, que eu veria com muita nitidez a identidade, ou melhor, a indestrutibilidade do homem primitivo, que permanece eternamente o mesmo em todas as épocas. (Michaud, 2013: 259)

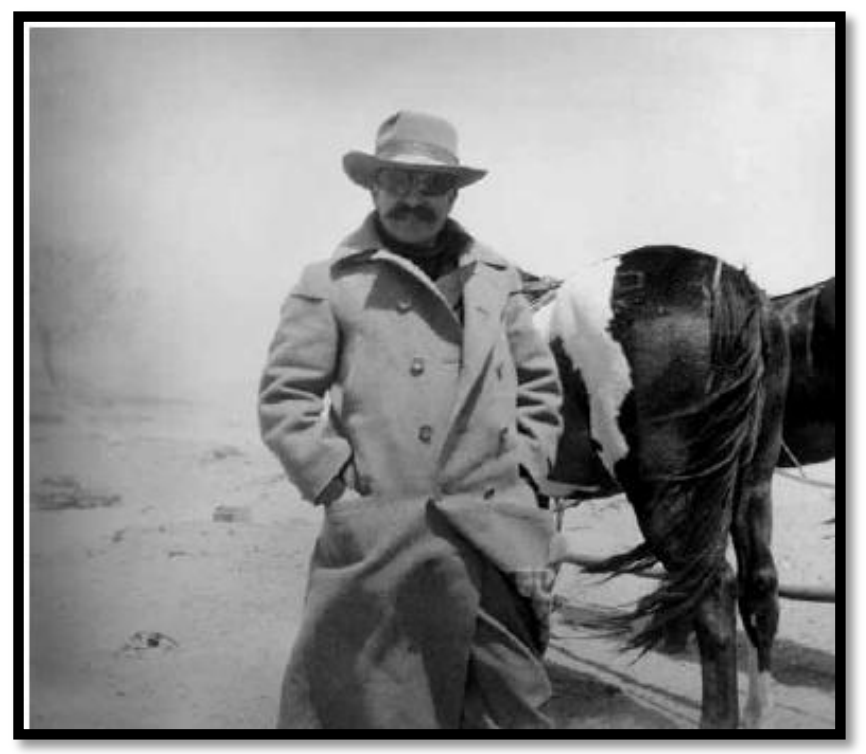

Figura 2-Aby Warburg ${ }^{4}$ 


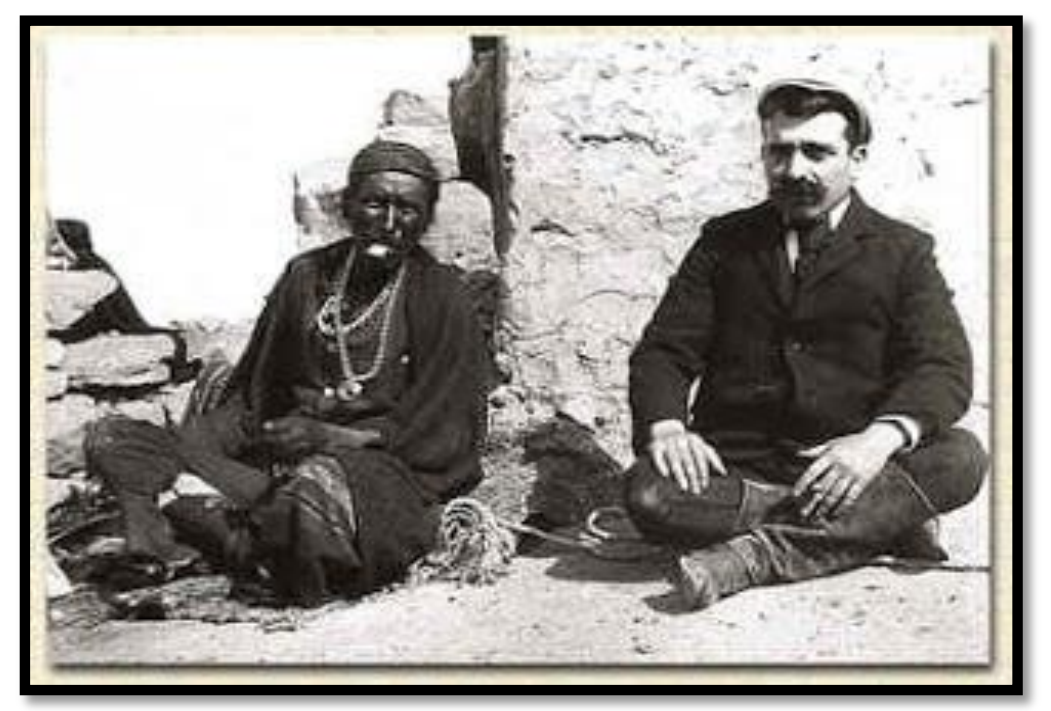

Figura 3 - Warburg com um índio Hopi, 1895-96

Os textos escritos por Warburg sobre a convivência com povos primitivos tratam de elementos que sugerem tanto uma justificativa para a elaboração de uma resposta que comprovassem sua teoria sobre a sobrevivência das imagens antigas, quanto a perspectiva de um Warburg antropólogo. Sobre este posicionamento ambíguo do historiador quanto aos objetivos de sua viagem, Michaud (2013: 181) afirma que "aos olhos de Warburg, a viagem ao Novo México não se limitava a um deslocamento na ordem dos saberes, mas era também uma parábola do rompimento com a melancolia".

Warburg buscou nesta viagem um contato muito próximo com índios das tribos isoladas que ainda mantivessem vivos rituais pagãos livres de interferências externas que pudessem corromper de alguma forma o modo como era constituído ou praticado. Buscava informações concretas e relevantes para a comprovação de sua tese - o processo de ressurgimento de certos elementos imagéticos ao longo da história. Esta pôde ser comprovada por meio desta viagem de motivos inicialmente particulares, mas que alavancou o significado geral de sua proposta.

O sentido de minha viagem é este: conhecer não apenas o Oeste dos Estados Unidos em geral, mas também, em particular, a região que tem uma significação essencial para a história dos povos vernaculares da América, o território que se encontra no ponto de junção entre Utah, Colorado, Novo México e Arizona.(Michaud, 2013: $183)$.

Seguindo leituras do livro de Gustav Nordenskiöld, filho de um importante explorador que já havia estado naquele território, Warburg entra em contato com uma região chamada Mesa Verde, lugar de origem dos índios Pueblos. Foi por intermédio de

\footnotetext{
${ }^{5}$ Arquivo do Instituto Warburg. Fonte: Michaud (2013: 251).
} 
uma visita que fizera a uma exposição de Nordenskiöld que Warburg acaba por conhecer outras figuras importantes de alguns pioneiros de Mesa Verde, como a família dos Wetterhill. O interesse pelos Pueblos deu-se em função de que, segundo ele, estes índios conservavam parte de seu estilo de vida antigo (Michaud, 2013: 183).

Sua peregrinação continua por vários territórios indígenas, sítios abandonados, aldeias e ruínas de antigas civilizações onde procurava presenciar e testemunhar diversos rituais das tribos pelas quais passava. No Arizona, entrou no território dos índios Hopi. Depois conheceu os Walpi e os Oraibi, que lhe proporcionaram uma enorme quantidade de documentos, fotografias e anotações. De acordo com Michaud, posteriormente Warburg acaba reconhecendo o quanto a viagem à América havia contribuído para sua pesquisa em uma carta escrita a James Mooney em maio de 1907. Warburg declara sua gratidão por todas as oportunidades que tivera durante esta viagem, especialmente quando afirma que "sempre me senti profundamente grato a seus índios. Sem o estudo da cultura primitiva deles, eu nunca teria criado condições para dar uma base ampla à psicologia do Renascimento". (Warburg apud Michaud, 2013: 187).

Há que se pensar o quanto as pesquisas de Warburg pautaram-se em uma tendência antropológica ou etnográfica apesar de seu objetivo fundamental não ser especificamente a pesquisa sobre grupos indígenas, mas a busca por comprovar a existência ou o reaparecimento de certos elementos imagéticos pagãos por meio da pósvida das imagens. Ao pensar sobre esta perspectiva, Warburg instituiu, consciente ou inconscientemente, com seu trabalho uma antropologia da imagem. Este ponto de vista o vinculava definitivamente ao estudo do homem pensado a partir da análise das imagens produzidas por ele ou sobre ele. As imagens passavam a ser pensadas como elementos culturais e percebidas como texto que continham alto grau de informação. Para Alves (2005: 15):

O objetivo principal desse ramo esquecido da antropologia seria o de estudar a
distribuição geográfica das formas na arte primitiva, projeto que estava maculado
por uma perspectiva evolucionista, tratava-se de definir linhas sequenciais de formas
afim de reconstruir um passado perdido através de suposições extraídas das
conclusões fundamentadas na distribuição ainda visível e encontrada nos povos
primitivos.

Há nesta viagem em busca da cultura primitiva e de rituais pagãos, a comprovação de uma ligação estreita com o trabalho de campo praticado pelo etnógrafo já que ele conviveu e documentou a vida nas aldeias por meio de diários de campo, de fotografias (tiradas por ele mesmo) ou de relatos produzidos em infinitas cartas. Várias destas 
informações podem ser conferidas também em publicações de outros autores, pois poucos resultados desta viagem foram publicados diretamente por ele. O relato mais conhecido sobre esta passagem da vida do historiador foi, sem dúvidas, a Conferência de 1923, em Kreuzlingen.

Graças a todas estas descobertas e aquisições, a viagem ao Novo México tornouse claramente um marco em sua carreira ao possibilitar a presentificação de representações aparentemente extintas. Através delas Warburg pôde perceber o estabelecimento de conexões com elementos imagéticos pagãos vistos somente durante o primeiro Renascimento. Sobre estas conexões entre períodos distintos e as constatações por ele percebidas, Michaud (2013: 189) argumenta que "aos olhos de Warburg, o Novo México, já não era apenas um análogo da Florença renascentista, no qual se reproduziam ao vivo os processos de figuralidade; tinha-se tornado a metáfora geográfica do próprio pensamento do historiador".

Há que se notar ainda a existência de muitos pontos de semelhança entre o trabalho de campo promovido por Warburg e a pesquisa etnográfica possibilitando a abertura a determinadas relações a serem exploradas. Cabe notar como filósofos e historiadores da arte como o próprio Didi-Huberman reafirmam esta ideia ao sugerir que:

\footnotetext{
Durante sua viagem à terra dos índios do Novo México, ele pediu a seu informante, Cleo Jurino - que era sacerdote-pintor de uma kiva sagrada -, que lhe desenhasse a famosa cobra-relâmpago da mitologia hopi [...]. Assim fazendo, agiu como um bom etnólogo, [...] procurando definir a casuística das "fórmulas gráficas primitivas". (Didi-Huberman, 2013: 191)
}

Atualmente, é possível levar em consideração a ideia de um Warburg antropólogo (Figura 4) graças às conexões possibilitadas pela postura assumida por ele enquanto convivia com grupos isolados. Esta afirmação surge a partir de uma perspectiva que denota um pesquisador em busca de definições que o levariam a um caminho cujos objetivos eram claramente antropológicos (Figura 5). Para Alves, Warburg teria consciência do procedimento a ser adotado no trabalho de campo e teria tomado todos os cuidados necessários à obtenção de informações.

[...] Haveria mesmo uma tentativa, ou ensaio de tornar-se antropólogo. As motivações psicológicas estão totalmente ausentes de seu relato, e as inclinações para o pensamento ocidental também. Não há desconfiança em relação ao intento de Warburg ou ao seu projeto, ele desejava produzir uma etnografia ou ao menos contribuir para com um problema importante da antropologia de sua época. (Alves, 2005: 15) 


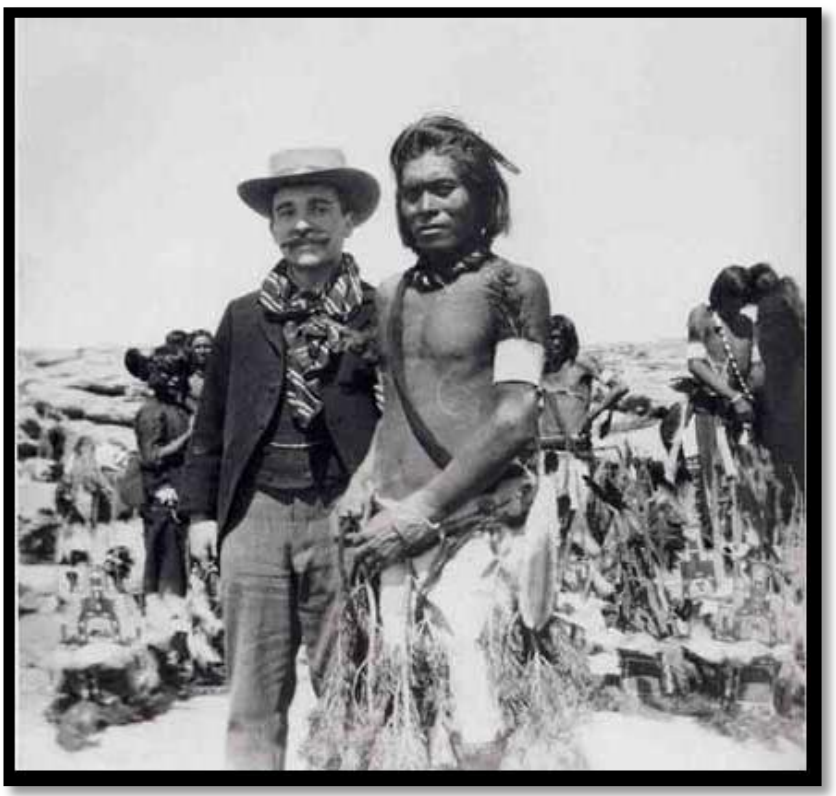

Figura 4- Aby Warburg com um índio ${ }^{6}$

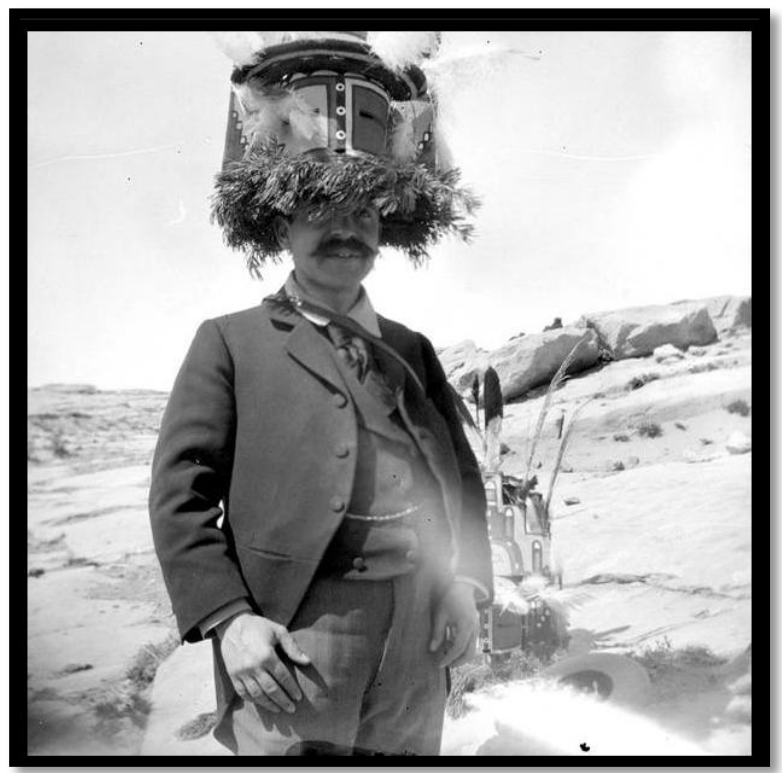

Figura 5 - Aby Warburg com uma máscara de dançarino katchina. ${ }^{7}$

${ }^{6}$ Arquivo do Instituto Warburg. Fonte: Michaud (2013: 246).

${ }^{7}$ Arquivo do Instituto Warburg. Fonte: http://warburg.sas.ac.uk/archive/. Acesso em: 22 de jan. de 2013. 


\section{Considerações Finais}

A antropologia buscou com os estudos sobre certos grupos humanos chegar à essência do conhecimento do homem, por meio da inserção, da convivência e do relato. Posteriormente, ela descobre na imagem um referencial potente para amparar ou conduzir suas pesquisas.

No entanto, a imagem sempre carregou consigo conteúdos, ora mais subjetivos, ora mais explícitos, que diziam sobre o homem e traziam consigo referenciais e potenciais, muitas vezes, desconhecidos ou ignorados pela antropologia ou pela história da arte. Aby Warburg demonstrou reconhecer a potencialidade contida nas imagens, fossem elas reproduções de fotografias, de objetos artísticos ou recortes de jornais.

Mais do que mero elemento estético decorativo, a imagem prova que possui um potencial inenarrável perante, e sobre, a sociedade. Ela assume um caráter de relevância histórica ao ser percebida como parte de um processo cultural. Como portadora de códigos e símbolos que subtendem mensagens e permitem infinitas leituras.

Warburg utilizou-se das várias possibilidades do estudo da imagem para comprovar sua tese: de que existem elementos nas representações imagéticas que sobrevivem ao tempo e que conseguem permanecer presentes em diversos períodos da história. Utilizou-se claramente das bases de uma pesquisa antropológica graças às influências recebidas na academia.

No exato momento em que decide estudar e conviver com grupos isolados de índios americanos e permanecer entre eles para comprovar sua tese sobre a Nachleben der Antike - a existência de rituais pagãos intocados ainda no final do século XIX, Warburg desenvolveu um trabalho etnográfico e antropológico. A produção de fotografias, diário e cartas, ainda enquanto estava imerso na cultura indígena, do mesmo modo pode ser caracterizado como pesquisa antropológica.

Sendo assim, fica clara a postura antropológica adotada por Aby Warburg ao propor sua teoria sobre a Pathosformeln. História da arte e antropologia caminharam juntas para elucidar a hipótese da pós-vida das imagens propostas por este pesquisador. Entende-se que Warburg desenvolveu plenamente estas ideias e seu nome ficará para sempre registrado na galeria dos grandes intelectuais da arte e da antropologia. 


\section{Referências}

ABY Warburg com uma máscara de dançarino katchina. Arquivo do Instituto Warburg. Disponível em: 〈http://warburg.sas.ac.uk/archive/>. Acesso em: 22 de jan. de 2014.

ALVES, Caleb Faria. A imagem depois do ritual da serpente.In: XXIX Encontro Anual da ANPOCS - GT 10 Imagens e Sentidos: a produção conhecimento nas ciências sociais. Minas Gerais, 2005.2 Disponível em: http://portal.anpocs.org/portal/index.php?option=com_docman\&task=doc_view\&gid=3710\&Ite mid=318. Acesso em: 20 de mar. de 2014.

BAITELLO JUNIOR, Norval. A serpente, a maçã e o holograma: esboços para uma teoria de mídia. São Paulo: Paulus, 2010.

DIDI-HUBERMAN, Georges. A imagem sobrevivente: história da arte e tempo dos fantasmas segundo Aby Warburg. Trad. Vera Ribeiro. Rio de Janeiro: Contraponto, 2013.

FLUSSER, Vilém. O mundo codificado. Trad. Raquel Abi-Sâmara. São Paulo: Cosacnaify, 2007.

GEERTZ, Clifford. A interpretação das culturas. Rio de Janeiro: LTC: 1989.

MICHAUD, Philippe-Alain. Aby Warburg e a imagem-movimento. Rio de Janeiro: Contraponto, 2013.

NOVAES, Sylvia Caiuby. $O$ uso da imagem na antropologia. In: SAMAIN, E. (org.) $O$ fotográfico. São Paulo: Hucitec, 1998.

PRANCHA do Atlas Mnemosyne Arquivo do Instituto Warburg. Disponível em: <http://warburg.sas.ac.uk/archive/>. Acesso em: 22 de jan. de 2013.

RIBEIRO, José da Silva. Antropologia Visual, práticas antigas e novas perspectivas de investigação. In: Revista de Antropologia. Vol. 48, n 2, São Paulo, Julho, Dezembro, 2005.

SAMAIN, Etienne. As "Mnemosyne(s)" de Aby Warburg: Entre Antropologia, Imagens e Arte. In: Revista Poiésis, n 17, p. 29-51, Jul. de 2011.

SCARSO, Davide. Fórmulas e arquétipos, Aby Warburg e Carl G. Jung. Lisboa, 2006. Disponível em: <http://www.educ.fc.ul.pt/hyper/resources/dscarso/>. Acesso em: 28 de nov. de 2013.

TEIXEIRA, Felipe Charbel. Aby Warburg e a pós-vida das Pathosformeln antigas. n.5. p. 134147. 2010. Disponível em: 
〈http://www.historiadahistoriografia.com.br/revista/article/view/171 > Acesso em: 14 nov. 2013. 